\title{
Publisher Correction: Multiple concomitant mechanisms contribute to low platelet count in patients with immune thrombocytopenia
}

\section{Matías Grodzielski, Nora P. Goette, Ana C. Glembotsky, M. Constanza Baroni Pietto,} Santiago P. Méndez-Huergo, Marta S. Pierdominici, Verónica S. Montero, Gabriel A. Rabinovich, Felisa C. Molinas, Paula G. Heller 10 , Paola R. Lev \& Rosana F. Marta

Correction to: Scientific Reports https://doi.org/10.1038/s41598-018-38086-1, published online 18 February 2019

The original version of this Article contained extensive errors in the Reference list. References 13-23 were incorrectly listed as references $14-24$ respectively, and reference 24 was incorrectly listed as reference 13.

In addition, reference 26 was omitted and is listed below:

Page L.K. et al. The immune thrombocytopenic purpura (ITP) bleeding score: assessment of bleeding in patients with ITP. Br J Haematol, 138, 245-8 (2007).

Finally, the original version of this Article contained errors in the in-text citations.

In the legend for Table 1,

“* Median and range are shown. **Bleeding score was evaluated according to the ITP Bleeding Scale (IBLS) proposed by Page and col. comprising 3 grades: from 0 (none) to 2 (marked bleeding) assessed at nine anatomical sites by history over the previous week ${ }^{25}$."

now reads:

“*Median and range are shown. **Bleeding score was evaluated according to the ITP Bleeding Scale (IBLS) proposed by Page and col. comprising 3 grades: from 0 (none) to 2 (marked bleeding) assessed at nine anatomical sites by history over the previous week ${ }^{26}$."

In the Materials and Methods, under the subheading 'Cell culture',

"CD34-positive cells were obtained from umbilical cord blood or from product of leukapheresis by immunomagnetic separation (Miltenyi Biotech Ltd., Bisley, Surrey, UK) as described previously ${ }^{24 . "}$

now reads:

"CD34-positive cells were obtained from umbilical cord blood or from product of leukapheresis by immunomagnetic separation (Miltenyi Biotech Ltd., Bisley, Surrey, UK) as described previously ${ }^{25}$."

These errors have now been corrected in the HTML and PDF versions of the Article. 
(c) (i) Open Access This article is licensed under a Creative Commons Attribution 4.0 International License, which permits use, sharing, adaptation, distribution and reproduction in any medium or format, as long as you give appropriate credit to the original author(s) and the source, provide a link to the Creative Commons license, and indicate if changes were made. The images or other third party material in this article are included in the article's Creative Commons license, unless indicated otherwise in a credit line to the material. If material is not included in the article's Creative Commons license and your intended use is not permitted by statutory regulation or exceeds the permitted use, you will need to obtain permission directly from the copyright holder. To view a copy of this license, visit http://creativecommons.org/licenses/by/4.0/.

(C) The Author(s) 2020 